\title{
EL INDIGENISMO PERUANO Y MARIATEGUI
}

\author{
POR \\ EUGENIO CHANG-RODRIGUEZ \\ Queens College of the City University of New York
}

\section{DEFINICIÓN Y ORIGEN}

La trayectoria y definición del indigenismo han suscitado diversas interpretaciones y álgidos debates ${ }^{1}$. Para nosotros, el indigenismo es la etapa superior del indianismo. Ambos son movimientos que tienen como tema central al indio, exponen sus costumbres y aspiraciones, pero aquél se distingue por denunciar la explotación del aborigen, reclamar su plena incorporación a la vida nacional y mostrar la dualidad cultural, la bipolaridad socioeconómica. Ambos tienen su origen en los sermones de fray Antonio de Montesinos en Santo Domingo (1511), en la tesis humanista del jurista dominico Francisco de Vitoria (1486-1546) y en la campaña y escritos del Apóstol de las Indias fray Bartolomé de las Casas. (1474-1566). Ambos señalan la escisión dicotómica de la sociedad colonial, amos vs. siervos, e intentan cristianamente resolver el dilema. Frustrada la vía filantrópica cristiana y la legislación indiana promovida por De las Casas y Vitoria, la escritura se convierte en el medio para reclamar e impugnar imaginativamente. Así, tan pronto el amerindio y sus descendientes aprendieron a escribir el castellano, su protesta se extendió al reclamo impreso. Uno de los primeros americanos que pidieron justicia para los suyos fue el Inca Garcilaso de la Vega (1539-1616). Su concepto de la conquista y de la posición de indios, mestizos, criollos y españoles

${ }^{1} \mathrm{Cf}$. mi «Reseña histórica del indigenismo», Cuadernos (París), 17 (1956), pp. 61-69; Antonio Cornejo Polar, «El indigenismo y las literaturas heterogéneas: su doble estatuto sociocultural», Revista de Crítica Literaria Latinoamericana, 7-8 (1978), pp. 7-21; y Tomás G. Escajadillo, «Ciro Alegría, José María Arguedas y el indigenismo de Mariátegui», en Mariátegui y la literatura (Lima: Amauta, 1980), pp. 61-106. 
en la sociedad colonial está magistralmente detallado en sus Comentarios reales ${ }^{2}$. En la introducción a la obra, el mestizo peruano, con concepción neoplatónica, expresa el deseo de rescatar del olvido la cultura tradicional incaica, contrasta la situación de sus antiguos compatriotas con su destino bajo el régimen colonial y propone resolver la disgregada y conflictiva realidad en una síntesis platónica: el mestizaje. Los Comentarios reales se convirtieron durante los tres siglos de dominación española en una de las fuentes principales de la historia incaica. Con el pretexto de que en este libro mestizos e indios aprendían muchas cosas inconvenientes, el gobierno colonial prohibió su circulación después de debelar la revolución de Tupac Amaru II, asiduo lector de los Comentarios reales ${ }^{3}$.

Así como el Inca Garcilaso llegó a ser el más importante escritor mestizo del indigenismo, Felipe Guamán Poma de Ayala (¿1550-1615?) se convirtió en su más destacado cronista indio ${ }^{4}$. Poco antes de morir terminó de escribir su Primer nueva corónica y buen gobierno ${ }^{5}$. Escribir había devenido con Guamán Poma en un proceso violento, donde, con el nuevo medio de comunicación y de reclamo, forja una escritura transgresora y subversiva. En ella analiza el estado social de sus compatriotas durante las primeras décadas de la colonización, señalando a los opresores. No conforme con protestar por escrito, Guamán Poma pinta más de 400 dibujos para dejar constancia del caos administrativo de Nueva Castilla. Su crónica denuncia abusos y también ofrece soluciones. Entre otras cosas recomienda el retorno a un sistema comunal parecido al incásico y pide la reducción del horario de cada día de trabajo a diez horas. Guamán Poma dirigió su carta-crónica al rey de España, pues tenía la esperanza de que el monarca siguiera sus recomendaciones y pusiera fin a los

${ }^{2}$ La primera parte de los Comentarios reales se publicó en Lisboa en 1608. La segunda parte, Historia general del Perú, apareció póstumamente en Córdoba en 1617.

${ }^{3}$ Ricardo Rojas, Historia de la literatura argentina (Buenos Aires: Roldán, 1924), I, 306; y Juan Sebastián Ochoa, Los cronistas del Perú (Cuzco: Imprenta D. Miranda, 1946), p. 65.

${ }^{4}$ Le precedieron muchos, algunos de ellos ofrecieron un proyecto nacional, como el de Titu Cusi Yupanqui y los incas de Vilcabamba (1537-1572). Cf. Pablo Macera, «Los proyectos nacionales en el Perú», Diario de la República, Lima, 15 de enero de 1984, pp. 27-29, y R. Chang-Rodríguez, Violencia y subversión en la prosa colonial hispanoamericana (Madrid: Porrúa Turanzas, 1982).

${ }^{5}$ El manuscrito extraviado fue hallado por el bibliotecario alemán Richard A. Pietschmann en la Real Biblioteca de Copenhague en 1908. Paul Rivet lanzó la edición facsimilar en 1936, la cual se reimprimió en 1968. Hasta hoy, las mejores ediciones son: 1) la de John V. Murra y Rolena Adorno, con traducción y análisis textual del quechua de Jorge L. Urioste (México: Siglo Veintiuno, 1980), 3 vols., y 2) la de Franklin Pease (Caracas: Biblioteca Ayacucho, 1981), 2 vols. 
abusos. El documento del cronista-dibujante ofrece una visión diferente de la Conquista y de las primeras décadas de la Colonia: señala la injusticia y la explotación, cuestiona el sistema vigente y propone que se le reemplace con un «buen gobierno», basado en el modelo incaico.

Después de Guamán Poma, el interés indigenista continuó en los dos siglos siguientes, pero ningún trabajo tuvo la repercusión de la traducción castellana del drama incaico Ollantay, puesto en escena ante el revolucionario Tupac Amaru II, desafiando la prohibición de representaciones teatrales indígenas hecha por el virrey Francisco de Toledo doscientos años antes. Una vez aplastada la rebelión de José Gabriel Condorcanqui, en 1781, las autoridades virreinales volvieron a prohibir la representación del drama incaico en el vano intento de desalentar ctralquier manifestación reivindicatoria indígena.

\section{Bolívar y González Prada}

Cuando los criollos se contagiaron del fervor revolucionario de indios y mestizos, el movimiento redentor del aborigen americano adquirió otro carácter. En la literatura política del período independentista se hallan tres sentimientos fundamentales: 1) antiespañolismo; 2) asimiento a la tradición indígena, principalmente al incanato, y 3) optimismo exultante acerca del futuro de Hispanoamérica ${ }^{6}$. Así, por ejemplo, el 10 de febrero de 1825, Bolívar declaró ante el Congreso Peruano que el Ejército Libertador había devuelto a los hijos de Manco Capac la libertad que les quitó Pizarro ${ }^{7}$. Después de esta exaltación, no encontramos en el siglo xix trabajo sobresaliente a favor del indio hasta la obra de Manuel González Prada (1844-1918), quien durante su retiro en la hacienda Tutumo (18711879) escribió poemas importantes para el desarrollo del indigenismo literario de su país. En El Correo del Perú, el joven escritor dio a conocer tres baladas: "La cena de Atahualpa», «Las flechas del Inca» y «El mitayo» ${ }^{8}$. En la primera capta el sentir del inca ante el golpe trágico de Cajamarca y la traición de Pizarro. En la segunda, el soberano aparece con tres flechas. Cada una le pide algo diferente: que destroce las alas del cóndor anunciador del arribo de los forasteros; que desgarre el seno del tigre acechador, y que atraviese el pecho del conquistador. La última

\footnotetext{
${ }^{6}$ Concha Meléndez, La novela indigenista en Hispanoamérica, 1823-1899 (Madrid: Edit. Hernando, 1934), p. 61.

${ }^{7}$ Discursos y proclamas de Bolívar (París: Garnier, s. f.), p. 85.

${ }^{8}$ L. A. Sánchez, «Prólogo» a M. González Prada, Baladas peruanas (Santiago de Chile: Ercilla, 1935), p. 13.
} 
balada, la más citada, estudiada y antologada, trata de la resignación del indio explotado frente a la indiferencia constante del patrón.

Años después, en julio de 1906, González Prada publicó, en el periódico ácrata Los Parias, una cuarta balada, «Canción de la india», sobre la protesta de la esposa desgarrada, porque llevan a su compañero a morir en guerra fratricida. Otras, algunas inconclusas, permanecieron inéditas hasta que su hijo Alfredo las reunió junto con las cuatro primeras en el poemario Baladas peruanas, publicado, con introducción de Luis Alberto Sánchez, en Santiago de Chile en 1935. La prosa de González Prada es igualmente solidaria con la causa indígena. En su discurso conmemorativo del día nacional (1888), don Manuel afirma que el Perú está poblado principalmente por indios semicivilizados, y que si se les alfabetizara recuperarían muy pronto su dignidad humana. A fines de ese mismo año, en su ensayo «Propaganda y ataque», declara que el indio, el verdadero substrato de la nación, sigue como en los tiempos coloniales, con el agravante de que durante la república se le había matado «lo que rara vez muere en el hombre: la esperanza» ${ }^{9}$.

Por su franca y persuasiva campaña, González Prada inicia una nueva etapa indigenista en el Perú. Bajo su influencia, en 1885, año de la revolución de Atusparia en Huaraz ${ }^{10}$, Mercedes Cabello de Carbonera publicó «Una fiesta religiosa en un pueblo del Perú», artículo con parecida vena redentora a los trabajos mencionados de don Manuel. En ese mismo año, José Torres Lara, con el seudónimo de José T. Itolararres, publicó la novela La trinidad del indio o Costumbres del interior, estructurada con una colección de cuentos en los que su autor se adelanta en medio siglo al mejicano Gregorio López y Fuentes en el uso de tipos en vez de personajes con nombres propios: «el cura», «el juez de paz», «el costeño». En 1889, Clorinda Matto de Turner (1852-1909) lanzó en Buenos Aires su novela Aves sin nido, dedicada a don Manuel, su compañero del Círculo Literario, que le había reafirmado en su fe indigenista. La crítica ve en esta obra la iniciación de la novela indigenista de América porque en ella el indio deja de ser adorno literario para convertirse en protagonista que sufre bajo la antigua trinidad explotadora: el poder político, el religioso y el económico. En ella, el gamonal está implícitamente presente: es el abastecedor del lanero codicioso, que resulta aquí el arquetipo literario del feudalismo explotador. La perspectiva moral de la autora realza la inmoralidad de los notables, es decir, de los que se encuentran

${ }^{9}$ M. González Prada, Páginas libres (Lima: Colecciones Peisa, s. f.), p. 156.

${ }^{10}$ El levantamiento dirigido por el alcalde indio Atusparia comenzó el 2 de marzo de 1885. Véase Jorge Basadre, La multitud, la ciudad y el campo en la historia del Perú (Lima: Editorial Huascarán, 1947), pp. 244-247. 
en el ápice socioeconómico de la pirámide andina. Es injusto acusar a esta escritora por no ser suficientemente explícita para identificar abiertamente al gamonal. Su prerrogativa estética la conduce a trastocar con hábiles recursos literarios la realidad del espacio literario de sus personajes. No es cierto que por esto falle en su análisis de la realidad nacional. Al examinar una obra hay que tener en cuenta las limitaciones cronológicas, la ideología de la época y el grado de adoctrinamiento que alimenta la escritura. Su exposición debió de ser muy clara y muy atrevida para sus lectores inmediatos, pues ella sufrió persecución y destierro. No exijamos a escritores peruanos del siglo xIx la visión dialéctica del conflicto entre feudalismo y capitalismo que hoy tenemos. La dialéctica hegeliana y marxista todavía no se había difundido en el Perú de las últimas décadas del siglo xix. Para Clorinda Matto de Turner y los de su vanguardia intelectual, los dueños del Perú de entonces eran los mismos gamonales serranos y costeños emparentados íntimamente con los señores de la burguesía emergente. Todos pertenecían a las mismas grandes familias, eran parte del mismo sistema, aunque tuvieran diferentes mañas. Críticos más distantes del escenario de la autora, y menos parcializados por exclusivismos ideológicos, han avalado con más justicia los límites impuestos por el horizonte cronológico, y por su impacto social decimonono han comparado Aves sin nido con La cabaña del tío Tom (1852), escrita por otra gran mujer: Harriet Beecher Stowe (1811-1896) ${ }^{11}$.

Que escritores de talento abogaran por la causa indígena produjo gran alboroto en los círculos gubernamentales y en parte prolongó el exilio de Clorinda Matto de Turner y contribuyó al autodestierro de don Manuel a Europa (1890-1898). Varios años después de su retorno al país, en diciembre de 1905, el Maestro publicó anónimamente en Los Parias su artículo "La cuestión indígena» para denunciar la hipocresía de los periodistas y políticos pseudoindiófilos. Casi un año más tarde, en noviembre de 1906, a raíz de la brutalmente reprimida sublevación indígena de Chucuito, González Prada publicó de nuevo en Los Parias otro artículo a favor de la misma causa. De todos sus escritos con este tema, su ensayo «Nuestros indios» ${ }^{12}$ es el que mayor impacto causó al publicarse en 1924,

"Birds Without Nest: A Story of Indian Life and Priestly Oppression in Peru es versión inglesa de Aves sin nido, publicada en Londres en 1904.

${ }^{12}$ Incluido en la 2." ed. de Horas de lucha (Callao: Tipografía Lux, 1924), pp. 311-338, con la nota inicial de su esposa Adriana: «Este artículo no formaba parte de la primera edición de Horas de lucha...» Mariátegui lo reprodujo en Amauta, 16 (julio 1928), pp. 4-7, precedido y seguido de varios trabajos sobre el Maestro escritos por Antenor Orrego, J. Eugenio Garro, Luciano Castillo y el suyo intitulado "González Prada" (pp. 8, 13-14). 
unos meses después del retorno de Mariátegui de Europa. En ese ensayo, don Manuel afirma que, en la República, continuación del Virreinato, los indios son todavía víctimas del viejo orden, basado en la explotación del hombre por el hombre, padeciendo más que sus antepasados durante el coloniaje ${ }^{13}$. Su autor, empero, apenas tocó el problema de la tenencia de la tierra, como lo haría más tarde su discípulo Mariátegui. Sólo apuntó:

Donde las haciendas de la Costa suman cuatro o cinco mil fanegas, donde las estancias de la Sierra miden treinta y hasta cincuenta leguas, la nación tiene que dividirse entre señores y siervos.

Sin embargo, el Maestro sí señaló algunas pautas para la solución del problema, que veía más como cuestión económica y social que pedagógica. Decepcionado porque su prédica se perdía en el vacío, concluyó: o cambia la conciencia de los opresores o se los escarmienta por la fuerza ${ }^{14}$. Ese fue el mensaje indigenista legado a sus discípulos.

Aun antes de la muerte de González Prada, sus escritos estimularon a algunos jóvenes de vanguardia a la acción. En 1909, Pedro S. Zulen sugirió la educación indígena como tema para las «conversaciones» del Centro Universitario de San Marcos; Dora Mayer, en su discurso sobre la raza oprimida, propuso la creación de una sociedad destinada a defender los derechos de los indios. Unos meses más tarde, el 13 de octubre del mismo año, los dos amigos fundaron la Asociación Pro-Indígena y en 1912 iniciaron la publicación de su vocero mensual, El Deber Pro-Indígena, que sobrevivió hasta diciembre de 1917. El periódico informaba sobre las actividades de la asociación y las condiciones de vida en el interior del país; también denunciaba abusos documentados y publicaba trabajos literarios indigenistas. De 1909 a 1917, la Asociación fue el portaestandarte más importante de la causa indígena en el país.

\section{LA SUPERACIÓN DEL MODERNISMO}

Los primeros tres lustros de la literatura peruana de este siglo están signados por el apogeo literario de José Santos Chocano (1875-1934), cuya poesía, con tema indio, pertenece a la etapa final del Modernismo. Como se sabe, en el Perú, Chocano se había puesto a la cabeza de esta corriente literaria desde que González Prada prologó sus Poesías completas, publicadas en Barcelona a principios de 1902, mientras el bardo

${ }^{13}$ Horas de lucha, pp. 323-326.

${ }^{14}$ Horas de lucha, pp. 336-337. 
errante continuaba sus aventuras por Centroamérica. A Chocano se le admiraba por su eclecticismo estético, que él mismo había resumido en Alma América: Poemas indohispánicos (1906): «En el arte caben todas las escuelas como en un rayo de sol todos los colores» ${ }^{15}$. El poeta había aunado magistralmente objetivismo y subjetivismo, parnasismo y simbolismo; con todo, sus poemas sobre el indio no calaban porque lo usaba como simple decoración literaria.

Pronto el descontento con un modernismo gastado y artificial lleva a los escritores jóvenes a buscar otros caminos expresivos. En esta búsqueda de una nueva orientación para la literatura nacional retoman ellos la bandera indigenista, estimulados por los éxitos revolucionarios en México y Rusia. Atrás quedaba la mal llamada belle époque. Decimos mal llamada porque, curiosamente, no se ha aclarado para quiénes fue bella esa época, en que millones de peruanos padecían la miseria, el subdesarrollo y la dependencia que Mariátegui, desde 1924, criticó tan severamente. Abraham Valdelomar, «modernista terminal» ${ }^{16}$, publicó en Colónida (1916) uno de los primeros manifiestos indigenistas. El escritor puneño Federico More (1889-1955), perteneciente a esa vanguardia literaria, fue el autor del manifiesto, si así se puede llamar a su propuesta:

Quien literatura peruana pretende hacer, obligado está a inquirir en el alma de nuestros más remotos ancestrales... Debe subir el espíritu hasta los remotos milenios de los megalitos incaicos. Debe escudriñar la tradición, oír de boca del pueblo la rapsodia que, desde la boca de lejanísimo ancestral, viene hoy al último retoño de una raza que entre frío y alcohol aún pimpollece ${ }^{17}$.

Esta es la alternativa ofrecida por uno de los escritores más apasionados de la época. Su proposición se encuentra intercalada en su devastador artículo-reseña de La literatura peruana: 1535-1914, trabajo de 91 páginas de Ventura García Calderón (1866-1959), publicado dos años antes ${ }^{18}$.

En 1918, César Vallejo (1892-1938) publicó Los heraldos negros, poemario que, si bien abunda en imágenes modernistas, muestra una firme voluntad de superarlas. Sus poemas «Oración del camino», «Huaco»,

${ }^{15}$ Alma América (Madrid: Victoriano Suárez, 1906), p. VIII.

${ }^{16}$ Luis Monguió, La poesía postmodernista peruana (México: Fondo de Cultura Económica, 1954), p. 27.

${ }^{17}$ F. More, «La hora undécima del señor don Ventura García Calderón», Colónida (Lima), 2 (1 febrero 1916), p. 35 . El artículo apareció en dos entregas en Colónida, núm. 2, pp. 33-39, y núm. 3 (1 marzo 1917), pp. 22-25.

${ }^{18}$ (New York-Paris: Extrait de la Revue Hispanique, t. XXXI, 1914), 91. 
«Aldeana» y «Los arrieros» ${ }^{19}$ muestran un indigenismo «virginal», del que se ocupará Mariátegui ocho años más tarde. Vallejo conoció a Mariátegui el mismo año de la publicación de su primer poemario, pero entonces éste todavía no había abrazado el indigenismo. Se vincularon personalmente sólo unos meses antes y después del viaje de Mariátegui a Europa (1919-1923). El poeta norteño partió para París en junio de 1923 y no retornó más a su patria, pero desde allá escribió al director de Amauta y le remitió colaboraciones. Vallejo se fue decepcionado de la justicia peruana, que tan arbitrariamente le había apresado, y de la indiferencia del público ante su obra poética. En 1922 había publicado Trilce, libro vanguardista que muestra su dolor en versos herméticos, compuestos con vocablos sencillos y metáforas inusitadas. En este segundo poemario suyo, Vallejo comparte la pobreza, el hambre, la persecución, la incomprensión, la violencia, la soledad y la injusticia con sus hermanos indios y mestizos. $\mathrm{Su}$ indigenismo entreteje realidad y mito ${ }^{20}$ y constituye un paso hacia la solidaridad con el universal dolor del hombre, expresada después en Poemas humanos (1939) y España, aparta de mí este cáliz (1940).

En suma, cuando Mariátegui regresó de Europa en 1923 encontró un ambiente intelectual cambiado y agitado. Durante su ausencia, en 1920, el chiclayano Enrique López Albújar (1872-1966) había publicado Cuentos andinos, basados en su experiencia de juez rural, y Luis Alberto Sánchez (n. 1900) había presentado su tesis «Nosotros» para optar al grado de bachiller en letras de la Universidad de San Marcos. En su tesis, Sánchez postulaba que para crear una literatura nacional aún no existente

... debemos comenzar por libertarnos de lo exótico y de lo superfluo, de las importaciones extranjeras y de las frivolidades nuestras. La literatura peruana, para ser tal, debe reflejar y fundir todos los elementos que integran la nacionalidad, todos sus factores históricos y sociológicos... Nuestra literatura de hoy debe... ser Quechuista... El quechuismo es una "disciplina», una gimnasia indispensable para la mejor asimilación de todos los factores de la sociedad peruana ${ }^{21}$.

${ }^{19}$ C. Vallejo, Obra poética completa (Lima: Francisco Moncloa Editores, 1968), pp. 96, 97, 100-101 y 129.

${ }^{20}$ R. Paoli, «Observaciones sobre el indigenismo de César Vallejo», Revista Iberoamericana, 71 (abril-julio 1970), p. 342. Este y otros estudios sobre el indigenismo de Vallejo refuerzan mi brevísima respuesta en La literatura politica de González Prada, Mariátegui y Haya de la Torre (México: De Andrea, 1957), p. 181, n. 60, al reparo a mi inclusión de Vallejo en dicho movimiento hecha por Jorge Bacacorzo, "Actualización del indigenismo», La Crónica (Lima), 23 mayo 1956, pp. 7 y 29.

${ }^{21}$ Monguió, p. 92. 
Como se ve, este examen combina lo artístico con lo político y lo social, fusión típica del indigenismo literario en proceso de reactualización. Durante la ausencia de Mariátegui, su amigo Vallejo, como se ha señalado, había publicado en 1922 su poemario vanguardista Trilce, con una clara manifestación de libertad poética. Fuera del mundo literario también se habían hecho importantes aportes. José Sabogal (1889-1956), artista cajamarquino, retornó al Perú en 1919 con la pintura indigenista que había desarrollado en la Argentina. La difundió en la Escuela de Bellas Artes en Lima y en el Cuzco durante sus dos años de residencia allí. En 1921 exhibió sus cuadros en la capital peruana. Al año siguiente se casó con María Wiesse, futura biógrafa de Mariátegui. Su viaje de luna de miel a México lo reafirmó en el indigenismo pictórico, cultivado también por otros artistas peruanos: Julia Codesido, C. Sánchez Urteaga (Camilo Blas), Enrique Camino Brent, Jorge Vinatea Reynoso y otros artistas, con quienes visitará a Mariátegui en su casa de la calle Washington.

\section{LA CONVERsión INDIGENISTA DE MARiátegui}

Casi dos años después de su retorno al Perú, durante los cuales había escrito sobre Europa mientras recuperaba su salud, el 9 de diciembre de 1924, Mariátegui publicó su primer artículo sobre la causa que defienden sus amigos: «El problema primario del Perú». Ahí hace suyas las ideas del postrer artículo de González Prada, «Nuestros indios», cuando repite sus postulados más importantes: 1) El «problema de los indios es el problema de cuatro millones de peruanos... de tres cuartas partes del Perú... de la mayoría de la nacionalidad»; 2) «El Virreinato... aparece menos culpable que la República... La República ha pauperizado al indio, ha agravado su depresión y ha exasperado su miseria»; 3) «La causa de la redención del indio es una especulación demagógica de algunos caudillos»; 4) «El indio es el cimiento de nuestra nacionalidad... Sin el indio no hay peruanidad posible», y 5) «La solución del problema del indio tiene que ser una solución social» ${ }^{22}$.

Un año más tarde, a fines de 1925 , en sus artículos sobre «Regionalismo y centralismo», nuestro autor ya vincula el problema del indio al problema de la tierra. El no ve en la descentralización como reforma ad-

${ }^{22}$ Mundial, 9 diciembre 1924. Incluido en Peruanicemos al Perú, obras completas de J. C. Mariátegui, 11 (Lima: Amauta, 1970), pp. 30-34. Fragmentos incluidos en «El problema del indio», 7 ensayos de interpretación de la realidad peruana, obras completas, 2 (Lima: Amauta, 1959), pp. 29-40. 
ministrativa ningún adelanto para resolver el problema del indio ni el de la tenencia de la tierra, que considera idénticos. Juzga que la descentralización aumentaría el poder del gamonalismo ${ }^{23}$. Según Mariátegui, «el Perú tiene que optar por el gamonal o por el indio. Este es su dilema. No existe un tercer camino». Y como los nuevos regionalistas son ante todo indigenistas, no hay que confundirlos con los anticentralistas. Para los regionalistas, como para nuestro escritor, el problema del indio es el problema de la tierra, y su condena del centralismo es también un rechazo del gamonalismo ${ }^{24}$.

Es 1926 sumamente importante en el desarrollo del nuevo indigenismo. En ese año se publicó el poemario Ande, de Alejandro Peralta (n. 1899), escritor puneño, fundador del Boletín Titicaca y autor de Kollao (1907), libro de análoga orientación. En 1926, asimismo, apareció Ccoca, de Mario Chabes (seudónimo de J. Mario Chávez), escritor vanguardista influido por Trilce y poemarios ultraístas indoamericanos y europeos. Entre 1926 y 1928 aparecieron en el Perú varias revistas indigenistas además de Amauta: Attusparia, en Huaraz; Boletín Kuntur y Vórtice, en Sicuani; el ya mencionado Boletín Titicaca, en Puno; Chirapu y Wanka, en Arequipa; Inti, en Huancayo; La Sierra y La Región, en Lima, y Serranía, en Huánuco. A ellas les sucedieron después un buen número de periódicos defensores de esa corriente, incluyendo Labor, suplemento de Amauta.

Cuatro elementos contribuyeron a la eclosión nativista de este período: 1) la prédica de González Prada y sus compañeros; 2) la clarificación teórica de las bases de la literatura peruana, comenzada en la Universidad de San Marcos cuando José de la Riva Agüero y Osma (1885-1944) defendió su Carácter de la literatura del Perú independiente para optar al grado de bachiller en letras en 1905; 3) el deseo de trocar el cosmopolitismo y exotismo modernistas por un localismo nacionalista matizado con léxico peruano, y 4) el nacionalismo que pedía la incorporación del indio a la nacionalidad peruana, suscitado por la primera guerra mundial y las revoluciones mexicana y rusa ${ }^{25}$.

Es pertinente observar que, en la mayoría de sus cultivadores, la poesía indigenista de este período se expresa con la estética y la técnica vanguardista, suprimiendo la preceptiva, la métrica, la rima, y con mayúsculas y minúsculas dispuestas para impresionar la vista. Todos los escritores

${ }^{23}$ Mundial, 16, 23 y 30 de octubre y 13 y 20 de noviembre de 1925 . Reproducidos en Amauta, 4 (diciembre 1926), pp. 25-30, y en 7 ensayos, pp. 168-197. La cita corresponde a 7 ensayos, p. 174.

${ }^{24} 7$ ensayos, pp. 186-187.

${ }^{25}$ Monguió, pp. 87-93. 
de esta orientación, sin embargo, tuvieron en cuenta la recomendación de Luis E. Valcárcel de considerar al indigenismo como una doctrina plena de mística pro india. Mariátegui tuvo en cuenta esto cuando afirmó: «Porque el carácter de esta corriente no es naturalista o costumbrista, sino más bien lírico, como lo prueban los intentos o esbozos de poesía andina ${ }^{26}$. Conviene señalar que, curiosamente, gran parte de los cultivadores de este lirismo indigenista fueron mestizos que se expresaban en términos ininteligibles para la mayoría que defendían. En su favor debe argüirse que los poemarios no se escribían para ellos, sino por ellos: iban dirigidos a mestizos e indios cultos, a quienes se quería adoctrinar, y a blancos y mestizos opresores, a quienes se deseaba increpar. Con todo, los llamados a la rebelión no fueron tan claros como los de González Prada; por eso Luis Monguió ha observado muy acertadamente:

Quizás también la imprecisión que se nota en los términos de las incitaciones a la revolución que llenan la literatura y la poesía indigenista fuera debida a que lo que íntimamente quisieran los escritores fuese más bien la revolución hecha contra el criollo (étnico, social o económico) sobre la base de una multitud india (pobre) pero con una dirección mestiza (clase media). Refuerza estas sospechas el hecho de que Mariátegui y sus amigos marxistas fueran objeto de la repulsa de los indigenistas cuando plantearon el problema como una cuestión descarnada, básica y revolucionariamente social y económica ${ }^{65}$. Y las sospechas indicadas se hacen más vehementes todavía al observar que la virada del nativismo peruano, del indigenismo hacia el «cholismo», es casi simultánea en el tiempo con la aparición de un movimiento -el aprismo- esencialmente de clase media mestiza (y vocabulario «indoamericano») con vistas a la conquistad del Estado ${ }^{27}$.

Así, ganado por el indigenismo que ahora sobrepasaba linderos exclusivamente artísticos, Mariátegui recoge en Amauta desde su primer número, de septiembre de 1926, ensayos, historias, cuentos, poemas, dibujos y pinturas que muestran la preocupación por el presente y futuro de la mayoría india. En enero de 1927, a partir del quinto número de la revista, Mariátegui inició la sección «El proceso del gamonalismo: Boletín de defensa indígena», con la siguiente presentación: «A partir de este número, Amauta publicará mensualmente un boletín de protesta indígena,

${ }^{26} 7$ ensayos, p. 290.

${ }_{27}$ Monguió, p. 107. Su nota 64 cita tres de estos ataques tomados de La Sierra (Lima), 4 (abril 1927), pp. 4-5; 1 (enero 1927), pp. 4 y 2, en ese orden. La nota 65 menciona «El problema primario del Perú» y su polémica con L. A. Sánchez, sobre la que nos ocuparemos más adelante. 
destinado a denunciar los crímenes y abusos del gamonalismo y de sus agentes.» La nota señala que se publicarán las acusaciones documentadas «con el doble propósito de iluminar la conciencia pública... y de aportar una nueva serie de testimonios al juicio, al proceso del gamonalismo».

\section{LA POLÉMICA DEL INDIGESISMO EN «MUNDIAL»}

En este ambiente cargado de inquietudes intelectuales se desarrolló, en la revista Mundial, de Lima, la sonada polémica del indigenismo. Aunque en ella participaron varios escritores, como se puede apreciar en un libro sobre el tema publicado diecinueve años más tarde, José Carlos Mariátegui y Luis Alberto Sánchez fueron los principales contendientes ${ }^{28}$.

Parece que los antecedentes inmediatos de ese debate fueron: 1) el trabajo crítico «Sobre la psicología del indio», de Enrique López Albújar, publicado en el número 4 de Amauta de diciembre de 1926;2) dos artículos de Mariátegui acerca de «El indigenismo en la literatura nacional», insertados en Mundial del 3 y del 26 de enero de 1927; 3) el artículo informativo sobre «La nueva cruzada pro-indígena», seguido de los «Estatutos del Grupo Resurgimiento», que Mariátegui publicó en el número 5 de Amauta correspondiente al 5 de enero de 1927, y 4) la censura del indigenismo costeño «Nosotros los indios...», por José Escalante, publicada en La Prensa del 3 de febrero de 1927.

En el primer trabajo, López Albújar se muestra muy severo con la psicología del indio huanuqueño, a quien califica de «esfinge de dos caras: ... la primera le sirve para vivir entre los suyos; la segunda, para tratar con los extraños». Después de señalar algunas virtudes, lo declara «hipócrita, taimado, receloso, falso, interesado, venal, negligente, sórdido». Tras esta indocumentada aserción, el escritor ofrece setenta juicios, algunos de ellos tan falsos y contradictorios que resulta difícil comprender por qué fueron publicados en Amauta.

En el primero de sus artículos sobre «E1 indigenismo en la literatura nacional», Mariátegui afirma que el indigenismo literario se encuentra en un período de germinación, sin haber dado todavía sus flores y frutos, lo cual lo hace comparable con el «mujikismo» de la literatura rusa prerrevolucionaria, que cumplió una misión histórica. En el segundo artículo, nuestro escritor se ocupa de la dicotomía peruana: costeño criollo-serrano

${ }^{28} \mathrm{La}$ polémica del indigenismo, textos y documentos recopilados por Manuel Aquézolo Castro, prólogo y notas de L. A. Sánchez (Lima: Mosca Azul Editores, 1976). 
indígena, exagerando las diferencias de estos dos componentes de la peruanidad. Para Mariátegui, el auténtico indigenismo involucra una obra económica y política de reivindicación y no de restauración ni de resurrección. Estos dos trabajos de Mundial fueron incluidos al año siguiente en sus 7 ensayos.

En enero de 1927, también en el quinto número de Amauta, Mariátegui informó sobre la constitución del Grupo Resurgimiento en el Cuzco. Su artículo tiene el encabezamiento: «La nueva cruzada pro-indigenista», y ahí elogia a estos trabajadores manuales e intelectuales y da el elenco de sus fundadores: Luis E. Valcárcel, J. Uriel García, Roberto La Torre y otros respetados representantes del indigenismo cuzqueño. E1 artículo, asimismo, ofrece los nombres de las personas incorporadas al Grupo en sus primeras sesiones: Francisco Choquehuanca Ayulo, Dora Mayer de Zulen, Julio C. Tello, José Sabogal y otros. Luego el articulista observa:

Faltan aún varios más, entre otros César Vallejo, Antenor Orrego, Enrique López Albújar, Víctor Raúl Haya de la Torre, Julián Palacios, Gamaliel Churrata, Alejandro Peralta, Jorge Basadre, J. Eulogio Garrido... Yo me siento particularmente honrado por su incorporación.

Después de mencionar que el Grupo aparece en circunstancias en que recrudecen en el Cuzco "desmanes y crueldades del gamonalismo», Mariátegui opina que el indigenismo anuncia y prepara una profunda transformación nacional y que «quienes lo consideran una artificial corriente literaria, que se agotará en una declamación pasajera, no perciben lo hondo de sus raíces ni lo universal de su savia». Muy revelador de su identificación ideológica de entonces es el párrafo en que afirma:

Se cumple un complejo fenómeno espiritual, que expresan distinta pero coherentemente la pintura de Sabogal y la poesía de Vallejo, la interpretación histórica de Valcárcel y la especulación filosófica de Orrego, en todos los cuales se advierte un espíritu purgado del colonialismo intelectual y estético. Por los cuadros de Sabogal y Camilo Blas y los poemas de Vallejo y Peralta circula la misma sangre. En los apóstrofes de Valcárcel, de Haya de la Torre y de Gamaliel Churrata se encuentra idéntico sentimiento. Los identifica hasta cierta entonación mesiánica ${ }^{29}$.

Teniendo en cuenta los cuatro artículos anteriores y quizá lo que en la Costa se estaba escribiendo sobre el tema, José Angel Escalante (18831956) publicó "Nosotros los indios...», artículo que actuó de reactivo de

\footnotetext{
${ }^{29}$ Amauta, 5 (enero 1927), p. 1 de la sección «El proceso del gamonalismo».
} 
la polémica en Mundial. Escalante, diputado leguiísta y propietario del diario El Comercio, del Cuzco, indudablemente creía que el movimiento indigenista surgía para socavar las bases del régimen al que pertenecía y se decidió a probar lo imposible: que la política gubernamental a favor del indio ya estaba resolviendo el problema. Para probar su tesis, Escalante trae a colación la obra de Pedro S. Zulen, sin explicar que la ardua labor de este pensador peruano de origen chino se había realizado al margen y a menudo en desafío de la política interna gubernamental.

Según Sánchez, éstos fueron los «preliminares de la polémica» que lo llevaron a escribir en Mundial del 11 de febrero «Un insensato anhelo de demolición...», para comentar la «indolatría reinante» ${ }^{30}$. Aquí su autor sostiene que el movimiento indigenista gastaba tinta retórica porque algunos de sus defensores «hacen de él bandera... que siembra divisiones de zonas geográficas». Pero el debate no comienza propiamente con este artículo, sino con el que Sánchez publicó a la semana siguiente en Mundial: "Batiburrillo indigenista». En él se refiere a "las crueles y demoledoras apostillas de López Albújar» y señala que entre no pocos defensores del indio «hay excesiva improvisación y alarde retórico... No era así, está claro, como procedía Pedro Zulen, hombre abnegado, desinteresado, fervoroso y tenaz como pocos, y en cuyo nombre se calumnia mucho empeño sincero». Luego critica directamente a Mariátegui por oponer colonialismo a indigenismo y por amparar las aseveraciones de López Albújar, todo lo cual le lleva a encontrar «una incoherencia increíble entre el lema de los colegas indigenistas y las sugestiones que amparan y defienden, es decir, que entre lo sustantivo y lo adjetivo reina una oposición radical». El artículo termina con un párrafo cuyas dos oraciones centrales dicen: «Quisiera que estas palabras obligasen a un profundo examen de conciencia. El indigenismo lo agradecería y se renovaría la verdad» ${ }^{31}$.

Mariátegui respondió a Sánchez con «Intermezzo polémico», en el siguiente número de la misma revista. Le dice a su polemizador que mezcla y confunde las expresiones positivas y negativas del movimiento sin distinguir las teoréticas de las estéticas ni de las prácticas, pero, en cambio, está listo a exigir perfecta congruencia entre especulaciones críticas, afirmaciones doctrinarias e imágenes poéticas. Le recuerda que el estudio de López Albújar era «sobre la psicología del indio huanuqueño» y estaba precedido por una advertencia sobre la dualidad psíquica, y que la mayor parte de las observaciones correspondían a la actitud del indio ante el blanco. Termina diciéndole: «no me llame... 'nacionalista', ni 'indigenis-

${ }^{30}$ La polémica del indigenismo, p. 10.

${ }^{31}$ La polémica del indigenismo, pp. 69-73. 
ta', ni 'pseudo-indigenista'... Llámame simplemente socialista» ${ }^{32}$. En el número siguiente de Mundial, el del 4 de marzo, Sánchez publicó su «Respuesta a José Carlos Mariátegui». Ahí se declara nacionalista peruanista al mismo tiempo que se identifica como uno de los primeros en haber despertado el indigenismo siete años atrás. Después, Sánchez señala que en Amauta, Mariátegui ha dado cabida a artículos de la más variada índole, a escritos de los más encontrados matices, perfectamente distantes de su ideología, en contradicción con lo que había prometido en su «Presentación» inicial de esa revista. Le aclara que no está de acuerdo en que se exalte sólo el elemento indígena serrano, olvidando al cholo y al criollo. El artículo concluye haciéndole varias preguntas, incluyendo «¿No podría acordar un movimiento de reivindicación total y no exclusivista?» ${ }^{33}$.

A la semana del artículo anterior, Mariátegui publicó también, en el semanario Mundial, su «Réplica a Luis Alberto Sánchez». Aquí explica qué es nacionalismo, distinguiendo el europeo del de los pueblos coloniales: el primero es imperialista, reaccionario y antinacionalista; el segundo, revolucionario y confluyente con el socialismo. Después le responde a su contendiente que «el socialismo es un método y una doctrina, un ideario y una praxis». Mariátegui declara que su ideal es el Perú integral, no el colonial ni el incaico. Por eso defiende la reivindicación de las clases trabajadoras, sin distinción de costa ni de sierra, de indio ni de cholo, y luego añade:

El obrero urbano es un proletario; el indio campesino es todavía un siervo. Las reivindicaciones del primero - por las cuales en Europa no se ha acabado de combatir - representan la lucha contra la burguesía; las del segundo representan aún la lucha contra la feudalidad. El primer problema que hay que resolver aquí es, por consiguiente, el de la liquidación de la feudalidad, cuyas expresiones solidarias son dos: latifundio y servidumbre ${ }^{34}$.

Usando este artículo como arma con dos cañones, Mariátegui, en acápites finales, responde a Escalante con una evasiva. Le observa que el grupo Resurgimiento se ha encargado de contestarle con su primer manifiesto. Como en realidad éste no menciona a Escalente y se había

${ }^{32}$ Mundial, 25 de febrero de 1927, reproducido en Amauta, 7 (marzo 1927), pp. 37-38; y en Ideología política, obras completas de J. C. Mariátegui, 13 (Lima: Amauta, 1969), pp. 214-218.

${ }^{33}$ La politica del indigenismo, p. 81.

${ }^{34}$ Mundial, 11 de marzo de 1927, reproducido en Amauta, 7 (marzo 1927), pp. 38-39; y en Ideología politica, pp. 219-223. 
aprobado y circulado antes que «Nosotros los indios...», era obvio que Mariátegui lo usaba para evitar responderle directamente a ese «político avisado». Por coincidencia o por decisión del director de Mundial, en el mismo número del 11 de marzo, en que aparece el anterior artículo de Mariátegui, se publica también "Ismos' contra 'ismos'», de su contrincante. Ahí Sánchez redefine el término "perricholismo», creado por él años antes y recogido y elogiado por Mariátegui, para luego afirmar:

Dentro del indigenismo se agrupan, en cambio, los anhelos nacionalistas, el acercamiento al pueblo, el desdén por las aristocracias sociales, la afición a lo autóctono, el espíritu revolucionario. ¿Coinciden las tendencias con los títulos? ${ }^{35}$

Finalmente, en "Más sobre lo mismo», un nuevo artículo publicado en Mundial el 25 de marzo, Sánchez expresa su deseo de que este trabajo suyo sea el final del debate. Sin embargo, sostiene ahí que uno de los problemas más difíciles de resolver en la polémica indigenista es el de la explotación del indio por el indio mismo, el de quien traiciona su propia sangre para convertirse en «el principal exprimidor de su raza». Explica que ni extirpando el latifundio ni afianzando la comunidad se resolverá el problema si sigue existiendo «el indio explotador de su raza, que se vuelve tinterillo al contacto de la civilización y trueca su diploma de abogado... o su gineta de sargento por la artimañosa péndola del tinterillo o el temido látigo del gamonal». Sánchez reitera su deseo de ver una cooperación de todas las fuerzas vivas del Perú, de una integración, de un totalismo, de un esfuerzo común. Por eso «la lírica cuestión de la educación tiene también su importancia». Recuerda que en la revolución mexicana han marchado parejos el movimiento agrario y el movimiento educacional. Más adelante, el articulista escribe: «No sé si en el plan de los nuevos mesías del indigenismo entren medidas concretas acerca del latifundismo, enfermedad denunciada, pero no tratada» ${ }^{36}$.

Este artículo de Sánchez, aunque publicado en Mundial el 25 de marzo de 1927, debió de haberse redactado antes, porque, desde la semana anterior, Mariátegui había iniciado su serie de 14 artículos sobre «El problema de la tierra», que siguieron apareciendo semanalmente en Mundial, y que en 1928 recogió en sus 7 ensayos. En el primero de ellos, del 18 de marzo, su autor insiste en que el problema agrario peruano se presenta

${ }^{35}$ Mundial, 11 de marzo de 1927, reproducido en La polémica del indigenismo, pp. $97-100$.

${ }^{36}$ Mundial, 25 de marzo de 1927, reproducido en La polémica del indigenismo, pp. 94-96. 
ante todo como el problema de la liquidación de la feudalidad. La identidad surge porque la antigua clase feudal, disfrazada de burguesía republicana, conservó sus posiciones y sus latifundios. De acuerdo con esta tesis, para él las expresiones de la feudalidad sobreviviente son latifundio y servidumbre; consecuentemente, no se puede liquidar la servidumbre de la raza indígena sin liquidar el latifundio. En el segundo de estos artículos, publicado el 25 de marzo, Mariátegui explica cómo el problema indígena está subordinado al problema de la tierra: «La raza indígena es una raza de agricultores.»

Mariátegui, por su parte, también intentó finiquitar el debate, tornado personal por ambos lados, y publicó «Polémica finita», ya no en Mundial, sino en Amauta de marzo de 1927. Ahí refuta la acusación de Sánchez con respecto a que Amauta no ha respondido a su programa ni a sus ideas al dar cabida a artículos de la más variada índole. Explicando que se ha obrado así porque Amauta era una revista de doctrina social, económica, política, de arte, de literatura, etc. La presencia subsidiaria o episódica de un intelectual sin posición combatiente - afirma el polemista- no le resta sustancia ni energía, pues son admitidos sin peligro para su integridad y homogeneidad como accidentales compañeros de viaje: «Que Amauta rechace todo lo contrario a su ideología no significa que lo excluya sistemáticamente de sus páginas, imponiendo a sus colaboradores una ortodoxia rigurosa» ${ }^{37}$.

\section{EL INDIGENISMO EN «AMAUTA»}

Ya hemos discutido cómo José Carlos Mariátegui acepta un nombre quechua, así como grabados con motivos indígenas, para la carátula de su revista Amauta, publicada a partir de septiembre de 1926. Igualmente hemos visto cómo desde el primer número recogió material de escritores $\mathrm{y}$ artistas identificados con este poderoso movimiento.

En todos los números que dirigió, Mariátegui contribuyó a mostrar la importancia del indigenismo.

Concluido el debate con Sánchez, Mariátegui siguió publicando en Mundial sus trabajos sobre «El problema de la tierra», para él tan ligado al problema del indio.

Un trabajo publicado en Amauta merece especial atención: La «Carta al Grupo "Resurgimiento'», de Manuel A. Seoane, incluida en el núme-

${ }^{37}$ Amauta, 7 (marzo 1927), pp. 6 y 36. Reproducido en Ideología y política, pp. 225-228. 
ro 9 de Amauta. En ella el autor concuerda con González Prada y Mariátegui. Para ellos el problema del indio es principalmente económico; está vinculado a la organización social y al régimen de la propiedad:

Por eso... hay que insistir en que es un problema económico y no un problema racial. Es decir, que hay que reivindicar al indio porque es un explotado y no porque es un indio. No podemos olvidar que no todos los indios son explotados ni todos los explotados son indios. Y la injusticia es general para todos los que sufren el peso del privilegio ajeno...

La mejor forma de salvar a la Patria, declaró Manuel Ugarte, es empujarla al porvenir. Hagamos eso nosotros. Las banderas están desplegadas. La Alianza Popular Revolucionaria Americana, partido continental, condensa todas las aspiraciones que están gestando el porvenir.

Ese es el partido, el Frente Unico dentro del que hay que agruparse, el que ha recibido adhesiones tan importantes como la de la Unión Latino Americana, la Liga Anti-imperialista, y que ha merecido elogios de hombres de la talla de Romain Rolland, José Ingenieros, Alfredo Palacios y José Vasconcelos ${ }^{38}$.

Mientras insertaba en Amauta este rico material, Mariátegui remitía al semanario Mundial sus artículos sobre «El problema de la tierra». Antes de que se publicara el penúltimo, sufrió una desagradable experiencia. Amauta había aparecido hasta entonces sin interferencia gubernamental; mas ahora, tras el debate del indigenismo y las publicaciones de los números 8 y 9 , que confirmaban a su director como un marxista abierto al ideario americanista, el gobierno de Leguía, preocupado por la difusión de la revista y su influencia entre intelectuales y obreros, urdió el llamado complot comunista cuando se enteró del asalto de la policía inglesa al Consulado Soviético de Londres en busca de propaganda bolchevique. El ministro de Gobierno del Perú envió a sus hombres a allanar el local donde se reunía la sociedad editora Claridad, conforme una convocatoria a sesión publicada en los periódicos locales, como de costumbre. La misma noche del 5 de junio de 1927 apresaron en sus domicilios a decenas de dirigentes obreros y universitarios y a muchos intelectuales. Las protestas de grandes celebridades internacionales en favor de Mariátegui, y contra la clausura de su revista, obligaron al gobierno a permitir la reaparición de Amauta en diciembre de 1927, con su décimo número.

En su segunda etapa, "Segundo acto», de acuerdo con Mariátegui en

${ }^{38}$ Amauta, 9 (mayo 1927), p. 39. La polémica del indigenismo reproduce la carta de Seoane con un grave error tipográfico. En la p. 118, donde dice «condena todas las aspiraciones...», debe decir "condensa todas las aspiraciones...». 
el editorial del décimo número de Amauta, mantuvo su política a favor de la causa india hasta el número 29 (febrero-marzo de 1930), el último que dirigió. En esta segunda fase, su director continuó discutiendo «E1 problema de la tierra en el Perú: requisitoria contra el gamonalismo o feudalidad»; reanudó su «Boletín de Defensa Indígena» desde el número 11. En fin, siguió reproduciendo grabados, dibujos y pinturas de artistas indigenistas a la vez que cuentos, poemas, artículos y reseñas de escritores de la misma orientación.

Aunque progresivamente se va notando la radicalización de Amauta, como lo evidencia su editorial del número 17, Mariátegui sigue abrazando un socialismo abierto, a tal punto que estudiosos marxistas han señalado una «ligera inconsecuencia entre sus posiciones teóricas y metodológicas», tanto en sus 7 ensayos como en Amauta ${ }^{39}$.

\section{El indigenismo EN «EL proceso de la literatura»}

Con posterioridad al desagradable episodio de su prisión, Mariátegui prologó el libro indigenista Tempestad en los Andes (1927), de Luis E. Valcárcel, y enjuició favorablemente el primer tomo de La literatura peruana, de Luis Alberto Sánchez. En esta reseña felicitó a Sánchez por incluir la literatura incaica y resaltó la seriedad y contracción historiográfica e investigadora de su autor tanto como su cultura y talento ${ }^{40}$. Por otro lado, al tratar de «El proceso de la literatura peruana», Mariátegui concuerda con González Prada en que «toda actitud literaria, consciente o inconscientemene, refleja un sentimiento y un interés político»y, por tanto, depende de las demás categorías de la historia. Teniendo en cuenta esto, llamó al revolucionario Mariano Melgar «primer expresador de categoría» del siglo XIX, porque se muestra muy indio en su imaginismo primitivo y campesino. Rectificando a Riva Agüero, nuestro escritor considera al patriota arequipeño «el primer poeta peruano de esta literatura» ${ }^{41}$.

La concepción indigenista de Mariátegui es por entonces tan amplia que, cuando se ocupa de Abelardo Gamarra, «uno de nuestros literatos más representativos», encuentra en el arte jaranero de su prosa reminis-

${ }^{39} \mathrm{Cf}$. el trabajo de Américo Ferrari incluido en este volumen, y A. Melis, A. Dessau y M. Kossok, Mariátegui: tres estudios (Lima: Amauta, 1971), pp. 103-104.

${ }^{40}$ «'La literatura peruana', por L. A. Sánchez», Mundial, 3 de octubre de 1928. Incluido después en Peruanicemos al Perú, pp. 141-145, con una nota equivocada de los editores cuando indican que lo tomaron de Mundial del 24 de agosto.

${ }^{41}$ Mundial, 7 de mayo de 1926, recogido en 7 ensayos, pp. 231-233. 
cencias indigenas ${ }^{42}$. Siguiendo a marchas forzadas por el vasto terreno de la literatura peruana, se detiene con criterio de Taine sólo en algunas luminarias del firmamento estético nacional, sin ocuparse de Itolorarres, la Cabello de Carbonera y la Matto de Turner. Su análisis inteligente, agudo, pero hecho con apresuramiento periodístico, no reconoce otro indigenista hasta llegar a César Vallejo, en quien encuentra «por primera vez en nuestra literatura sentimiento indígena virginalmente expresado», con modulación propia y técnica y lenguaje nuevos. Mariátegui sostiene que cuando el sentimiento indigenista vallejiano aflora plenamente al verso, éste cambia su estructura: «En Melgar no es sino el acento; en Vallejo es el verbo. En Melgar, en fin, no es sino queja erótica; en Vallejo es empresa metafísica.» Para Mariátegui, lo fundamental en el autor de Los heraldos negros no es su simbolismo prestado de Herrera y Reissig, sino su nota india, que le comunica una frecuente actitud de nostalgia acendrada y le lleva a la ternura y a la evocación subjetiva. El crítico descubre que, en Vallejo, el fondo de pesimismo indígena con piedad humana no es un concepto, sino un sentimiento: "Tiene una vaga trama de fatalismo oriental, que lo aproxima, más bien, al pesimismo cristiano y místico de los eslavos» ${ }^{43}$. Mariátegui apenas se ocupó de Trilce. Cuando discutimos su polémica con Sánchez, tratamos los otros artículos suyos que formaron parte de la sección indigenista de «El proceso de la literatura», último capítulo de 7 ensayos.

\section{LAS CRUZADAS DE «LABOR»}

Con el propósito de complementar la obra de Amauta, José Carlos Mariátegui lanzó Labor, quincenario de información e ideas, que, pese a su subtítulo, apareció irregularmente. Sólo logró publicar diez números desde el 10 de noviembre de 1928 hasta el 7 de septiembre de 1929. Esta falta de periodicidad se debió en parte a dificultades económicas de la sociedad editora Amauta, que lo imprimía, y en parte a la interdicción policial. Según la nota de presentación en la primera página del número inaugurador, su aparición obedecía a instancias de muchos amigos de Lima y provincias, deseosos de que la obra cultural penetrara en capas más extensas del público. El número inicial incluyó, en sus páginas 5 y 7 , el cuento «Mañanas Collas», de Gamaniel Churata (seudónimo de Arturo Peralta, 1897-1969), escritor indigenista puneño y colaborador de Amau-

\footnotetext{
${ }^{42}$ Mundial, 14 de mayo de 1926, recogido en 7 ensayos, pp. 231-233.

${ }^{43}$ Mundial, 23 y 28 de julio de 1926, recogidos en 7 ensayos, pp. 268-275.
} 
ta. Mariátegui insertó asimismo su artículo «Sobre el problema del indio», presentado en la página 6, con apuntes que completan en cierta forma el capítulo con el mismo nombre de 7 ensayos. Su autor explicó que lo escribió para la agencia Tass de Nueva York. Después de dar una breve revisión histórica del problema, Mariátegui explica cómo la propagación de las ideas socialistas en el Perú había traído como consecuencia un fuerte movimiento de reivindicación indígena ${ }^{44}$.

En los siguientes números de Labor, como en Amauta, dedicó gran parte de su espacio a artículos indigenistas, reseñas de obras con este tema y a informar sobre las agresiones contra los indios llevadas a cabo en el país. En el octavo número, correspondiente al 1 de mayo de 1929, páginas 1-2, se reprodujo el discurso «El intelectual y el obrero», que don Manuel González Prada había leído el 1 de mayo de 1905 en la Federación de Obreros Panaderos. En sus dos últimos números (18 de agosto y 7 de septiembre de 1929), Labor dedicó gran espacio a su nueva sección «El ayllu: defensa de los trabajadores agrícolas, aspectos del problema de la tierra, proceso del gamonalismo». En el noveno número reprodujo, en las páginas 6 y 7, la extensa resolución sobre la organización de los trabajadores agrícolas y forestales, aprobada por el Congreso Sindical Latinoamericano, reunido en Montevideo poco antes; y acogió también ahí denuncias de despojos de tierras comunales en Jauja y Lambayeque. En la séptima página del número final, Mariátegui defendió el sistema de riego de los campesinos de Huacho, denunció la acción de despojo de tierras de la Comunidad de Pancán, una de las más adelantadas del departamento de Junín, e incluyó el artículo «Geografía del Siclla: su interpretación folklórica indígena», acerca del baile colonial que representaba la influencia judicial de la Real Audiencia, y que aún subsiste, porque la administración de justicia no ha mejorado durante la República.

Como se ha podido apreciar, Labor fue un periódico único en América Latina. No sólo se ocupó de los problemas de los trabajadores urbanos y rurales, sino que también dio cabida a cuentos, capítulos de novela y fragmentos de obras sociales. Este periódico combinó la información sobre la organización gremial con asuntos políticos, sociales y culturales. $\mathrm{Su}$ objetivo era claro: adoctrinar a los trabajadores sin descuidar ni su sentido de la colectividad ni su entrenamiento. Labor proponía la identificación histórica, social y gremial, pues quería crear conciencia nacional a la vez que ayudar en el proceso de sindicalización, a pesar de la

${ }^{44}$ Labor, 10 de noviembre de 1928, p. 6. 
prohibición oficial vigente desde $1927^{45}$. Labor no trató de popularizar la cultura en el sentido tradicional, diluida al nivel intelectual del trabajador pasivo no escolarizado; sí intentó aumentar el bagaje cultural de sujetos activos en la historia. El quincenario se dirigía a lectores capaces de ser dueños de su destino, en contraste con sus predecesores. Labor revela a Mariátegui como un político convencido de que el verdadero revolucionario no podía dejar a un lado la cultura. Dentro de ella, la literatura ocupa un lugar clave. El entrenamiento cultural propuesto por el Amauta está indisolublemente ligado al movimiento indigenista y sus diversas manifestaciones.

El décimo número, del 7 de septiembre de 1929, resultó ser el último porque, cuando el undécimo estaba ya por imprimirse, el gobierno clausuró Labor ${ }^{46}$.

\section{La tesis censurada en la Primera Conferencia Comunista LATINOAMERICANA}

Como se ha podido apreciar, la concepción mariateguiana del indio es más gonzalezpradista que bolchevique: el indio es un ser aparte de la sociedad; es elemento mayoritario de un país en vías de constituirse en nación. Mariátegui no estuvo de acuerdo con las teorías optimistas del futuro mestizo; no creyó en el neo-indio amestizado de Uriel García ni en la raza cósmica de Vasconcelos, "producto de la mezcla... de europeo con indio, con negro, con chino, con todas las razas conocidas, la raza mixta total, el primer caso de raza positivamente universal» ${ }^{47}$. Tal vez por eso afirma Augusto Tamayo Vargas: "Mariátegui se perdió en planteamientos de raza - hoy en desuso-e hirió a sectores de nuestra población»" ${ }^{48}$. Para Mariátegui, el indio difiere de los demás peruanos étnica y culturalmente y había que reivindicarlo en la economía y la literatura nacionales. Para él, como para los apristas, el problema del indio se

${ }^{45}$ David O Wise, «Labor (Lima, 1928-1929), José Carlos Mariátegui's WorkingClass Counterpart to Amauta», Revista de Estudios Hispánicos, 14, 3 (octubre 1980), 123.

${ }_{46}$ «'Labor' interdicta», Amauta, 26 (septiembre-octubre 1929), p. 92, y en Ideología y politica, p. 247.

47 José Vasconcelos, Obras completas (México: Libreros Mexicanos Unidos, 1957), II, 1137.

${ }^{48}$ L. E. Valcárcel y otros, El problema del indio..., Presencia y proyección de los 7 ensayos (Lima: Amauta, 1976), p. 88. Su observación concuerda con lo que dijimos en 1957 en La literatura política, pp. 182-183, y con lo notado por Nicomedes Santa Cruz en artículos publicados en diarios de Lima en 1967. 
identifica con el problema de la tierra. Así lo había señalado González. Prada, de quien ellos tomaron la consigna de la alianza de los trabajadores manuales e intelectuales, frase muchas veces usada en Amauta.

De estas convicciones surge su tesis «El problema de las razas en América Latina», donde Mariátegui analiza detalladamente la situación racial ${ }^{49}$. Fue presentada por la delegación peruana, que asistía, en calidad de observadora, a la Primera Conferencia Comunista Latinoamericana, reunida en Buenos Aires en junio de $1929^{50}$.

Según el autor de esta tesis, el problema de las razas en la América Latina debe plantearse como una cuestión económica, social y política, basada en el problema de la tierra, y, por tanto, su solución radica en la liquidación de la feudalidad ${ }^{51}$. Mariátegui llama problema indígena a la explotación feudal de la población nativa en la gran propiedad agraria ${ }^{52}$. Pero su visión del indígena ahora es amplia. Nos dice que se acepta generalmente la afirmación de incluir en la raza india a las cuatro quintas partes de la población total, apreciación que no tiene en cuenta estrictamente el factor étnico, sino más bien su condición económico-social:

Existen provincias donde el tipo indígena acusa un extenso mestizaje. Pero en estos sectores la sangre blanca ha sido completamente asimilada por el medio indígena, y la vida de los «cholos» producidos por estos mestizajes no difieren de la vida de los indios propiamente dichos ${ }^{53}$.

${ }^{49}$ La tesis consta de dos partes: «I. Planteamiento de la cuestión» y «II. Importancia del problema racial». La I, precedida por el título «Esquema del problema indígena», apareció en Amauta, 25 (julio-agosto 1929), pp. 69-80. La reprodujo R. Martínez de la Torre, Apuntes para una interpretación marxista de historia social del Perú (Lima: Empresa Editora Pertiana, 1947-1949), III, 16-29. Aquí tiene la. numeración de sus secciones cambiadas, con números arábigos en vez de romanos y con las palabras «al movimiento sindical» añadidas al título de la sección final. En el tomo II (436-466) se la reproduce incompleta. El séptimo párrafo se ha sustituido por otro sobre «La existencia de "razas inferiores'...». A continuación sigue la parte II completa con todas sus subdivisiones. La tesis íntegra aparece en Ideología política, pp. 21-86, con la nota de los editores explicando que en la redacción de la parte II, «sobre el esquema básico de Mariátegui, el Dr. Hugo Pesce aportó la mayor parte del texto» (pp. 46-86).

${ }_{50}$ Sobre si la delegación peruana asistió como observadora o no, véase "Aricó sobre Mariátegui», El Caballo Rojo, suplemento dominical al Diario de Marka, I, 16 (Lima, 31 de agosto de 1980), pp. 3-5 y 12; y Ricardo Luna V., «Mariátegui no se batió en retirada (Aricó, sí)», Unidad (Lima), 4-11 de septiembre de 1980, p. 7.

${ }^{51}$ Ideologia y política, p. 21.

${ }^{52}$ Ideología y politica, p. 25.

${ }^{53}$ Ideologia y politica, p. 34. 
La población indígena así considerada trabaja mayoritariamente, en su 90 por 100, según Mariátegui, en la agricultura, bajo condiciones feudales o semifeudales. Niega que el indio sea incapaz de luchar por sus reivindicaciones, dando como prueba las innumerables insurrecciones y asonadas indígenas, entre las que destaca la encabezada por el mayor del ejército peruano Teodomiro Gutiérrez, mestizo serrano que se hacía llamar Rumimaqui. Derrocado el gobierno de Billinghurst, se levantó en armas en Puno, seguido por millares de indígenas que, como él, se daban cuenta que con el derrocamiento del gobierno constitucional desaparecían las perspectivas de reivindicaciones legales ${ }^{54}$.

$\mathrm{Si}$, por una parte, Mariátegui no cree que el problema sea racial, sino social y económico, por otra sostiene que la «raza tiene su rol en él y en los medios de afrontarlo», por eso «sólo militantes salidos del medio indígena pueden, por la mentalidad y el idioma, conseguir un ascendiente eficaz e inmediato sobre sus compañeros ${ }^{55}$. La importancia de lo racial es tan obvia que, en los países con población india, el factor raza se complica con el factor clase, de tal manera que una política revolucionaria debiera tener en cuenta que

el indio Quechua y Aymara ve su opresor en el «misti», en el blanco. $\mathrm{Y}$ en el mestizo, únicamente la conciencia de clase es capaz de destruir el hábito del desprecio, de la repugnancia por el indio. No es raro encontrar entre los propios elementos de la ciudad que se proclaman revolucionarios el prejuicio de la inferioridad del indio y la resistencia a reconocer este prejuicio como una simple herencia o contagio mental del ambiente ${ }^{56}$.

Hasta aquí las ideas principales de Mariátegui en la primera parte de la tesis que, con el nombre de «Planteamiento de la cuestión», se presentó a la Primera Conferencia Comunista de Buenos Aires de 1929. La segunda, «Importancia del problema racial», la redactó el Dr. Hugo Pesce sobre el esquema básico de Mariátegui. El Dr. Pesce, como miembro de la delegación peruana, presentó el trabajo de Mariátegui. Las dos partes reunidas bajo «El problema de las razas en la América Latina» fueron severamente criticadas por los más altos dirigentes del Komintern reunidos alli ${ }^{57}$.

${ }^{54}$ Ideología y politica, p. 40.

${ }_{55}$ Ideología y política, p. 45.

${ }^{56}$ Ideologia y política, p. 48.

${ }^{57}$ R. Martínez de la Torre, Apuntes, II, 466-476. 
De esas objeciones sólo citaré la del «camarada Peters», delegado de la Internacional Juvenil Comunista:

Al plantear el problema de los indios, es preciso evitar algunos errores...; reducir la cuestión nacional a la cuestión de clase, a la cuestión agraria, porque esto significaría olvidar, justamente, las condiciones históricas de las luchas contra los conquistadores, etc.; peculiaridades que han determinado a los revolucionarios marxistas a proclamar, al lado de las reivindicaciones de clase, la consigna, para nosotros fundamental, del «derecho de los pueblos a disponer de ellos mismos, hasta el derecho de separación». Según mi opinión, la confusión de algunos de los camaradas peruanos sobre el contenido nacional del problema indígena en el Perú los conduce a estar contra esta consigna, que me parece debe ser lanzada por nuestros partidos allí donde existan masas compactas de indígenas ligadas con la cuestión de la tierra, que da a la lucha de los indígenas el aspecto de lucha nacional. En este sentido, los casos de Bolivia y el Perú son característicos ${ }^{58}$.

A propósito de este debate, durante el cual se propuso la eventual desmembración del país, el historiador Jorge Basadre ha comentado:

La actitud peruana recibió severas críticas y obtuvo un rechazo absoluto. La tesis indigenista de Mariátegui, voceada por Pesce, en el sentido de que el problema indígena debía ser tratado como problema de clase para hacer del aborigen un aliado del proletariado de otras razas, fue contradicha por la consigna del «derecho para la autodeterminación» que lleva en sí la eventualidad de repúblicas quechuas y aimaras ${ }^{59}$.

Hugo Pesce retornó de Buenos Aires en julio de 1929 y le informó a Mariátegui de las objeciones de la Internacional Comunista, tanto a sus tesis indigenistas como a las otras dos tesis políticas enviadas con la delegación peruana. Su precaria salud continuó deteriorándose. Unos meses más tarde, el 16 de abril de 1930, falleció el Amauta.

${ }^{58}$ Que en Moscú desde antes objetaban las ideas indigenistas de Mariátegui se infiere de la intervención en el Congreso de su compatriota, el «camarada Zamora» (Julio Portocarrero): «Cuando estuve en Moscú, se ponían reparos de parte del compañero Dujovne a mi interés de que se trate [sic] el problema indígena, que por sus características es apto para la penetración de nuestra propaganda.» $Y$ en párrafo seguido: «El compañero Peters, para reforzar su argumentación, traía citas de Lenin (contra Rosa Luxemburgo), que consideraba que la libre determinación de los pueblos era una concepción absolutamente marxista.» $R$. Martínez de la Torre, Apuntes, II, 471.

${ }_{59}$ La vida y la historia: Ensayos sobre personas, lugares y problemas (Lima: Banco Industrial del Perú, 1975), p. 233. 


\section{El legado indigenista de Mariátegui}

Como se ha visto, José Carlos Mariátegui supeditó su concepción del indigenismo a su ideario socialista. Con criterio marxista personal, interpretó el problema del indio superando a sus predecesores. Después de considerar las posibles opciones suscitadas por el tema en diversos campos, Mariátegui esbozó su planteamiento. En él ya no mencionó la existencia de una dicotomía nacional, Costa criolla versus Sierra indígena. Hizo bien, porque, después de todo, la Costa no es toda criolla ni la Sierra completamente india. El Perú no tiene una naturaleza bimembre, bipolar, dicotómica y antinómica: es un país multiforme, con gran diversidad de componentes tanto en sus aspectos sustantivos como adjetivos. El indio no es sino parte de un todo abigarrado, a la vez multicultural y multilingüe. Tal vez sí la comprensión de esta realidad explique la rectificación de Mariátegui cuando, en su tesis final, hace suya una posición totalista. La delegación de cuatro peruanos asistentes como observadores al Primer Congreso Comunista Latinoamericano de 1929 defiende la tesis de Mariátegui contra las objeciones de la Internacional Comunista e interpreta correctamente a su autor cuando se opone a la creación de un estado quechua y un estado aymara justificados por la consigna de defender el principio de la autodeterminación y la supuesta arbitrariedad de las actuales fronteras del Perú y Bolivia.

Para Mariátegui, la cuestión del indio, como los demás problemas básicos del país, gira alrededor de la economía; consecuentemente, la revolución socialista puede resolverlos aniquilando la feudalidad. Su indigenismo no es antihispánico, sino antigamonal. Como González Prada, cuando defiende al indio no agrede al blanco. Su oposición al servilismo afecia al patrón, sea éste criollo, blanco, mestizo e indio. La reflexión de Mariátegui es económica y no étnica. Cuando elaboró su última tesis tuvo en cuenta la totalidad peruana, que percibe con criterio dialéctico consonante con un socialismo abierto, receptor de los aportes positivos de sus compatriotas, a quienes debate y enseña, pero de quienes también aprende. Su política editorial en Amauta y en Labor demuestra cómo la prédica indigenista debe llevarse a cabo utilizando todos los vehículos y campos de expresión posibles: económico, político, sociológico, histórico, pictórico y literaro. Así se crea una conciencia propicia a la solución del problema. En último análisis, éste tiene su origen en las dislocaciones económicas incrustadas en el mundo nativo por fuerzas extrañas.

Este legado de Mariátegui influirá decisivamente en la literatura indigenista posterior, sobre todo en la de sus más altos exponentes: Ciro Alegría (1909-1967) y José María Arguedas (1911-1969). Ambos comien- 
zan a publicar novelas y cuentos en 1935, apenas un lustro después de la muerte del Amauta ${ }^{60}$. Mariátegui les mostró con más claridad que la dicotomía socioeconómica peruana contrapone el mundo semifeudal indígena y el universo mestizo-blanco capitalista, servidor del imperialismo extranjero, consciente o inconscientemente. En ese Perú dual, el segundo ejerce el poder hegemónico. Estos dos novelistas, continuadores del indigenismo de Mariátegui, tratan de resolver la problemática nacional utilizando artísticamente el espacio rural, en el cual el tiempo histórico, con su carga de luchas humanas, se impone al tiempo mitológico. En sus obras, el indio aculturado y concienciado escucha la admonición gonzalezpradiana y escarmienta al abusivo patrón impulsado por las fuerzas económicas clarificadas por Mariátegui. Ciro Alegría, en El mundo es ancho y ajeno (1941), empieza el drama de la comunidad india, que explica su desplazamiento con interpretaciones míticas, augurios y ofrendas exorcizantes. En los capítulos finales se impone la dinámica histórica, y Benito Castro, el nuevo protagonista que reemplaza a Rosendo Maqui, conduce a su comunidad a la lucha contra las fuerzas que apoyan al gamonal, utilizando el entrenamiento que ha recibido fuera del mundo indio. En Todas las sangres (1964), de José María Arguedas, el protagonista Benito Rendón, como Benito Castro, igualmente aprende fuera del universo indígena la táctica revolucionaria que ayudará a los suyos a fuchar por la justicia.

Como se ha podido apreciar, la interpretación mariateguiana de la realidad peruana contribuyó a ampliar los horizontes del indigenismo al recalcar la intención reivindicativa y la revalorización del mundo indio. El aporte de Mariátegui enriqueció al movimiento en los diversos géneros, y décadas después de la muerte prematura del Amauta continuó dando nuevos frutos. Sebastián Salazar Bondy y los críticos promotores del boom literario hispanoamericano se equivocaron al anunciar el agotamiento del indigenismo en la década del sesenta ${ }^{61}$.

60 E. Chang-Rodríguez, «Mariátegui y Sánchez en la redefinición del indigenismo», en Narradores latinoamericanos (1929-1979), Memorias del XIX Congreso Internacional de Literatura Iberoamericana (Caracas: Ediciones del Centro de Estudios Latinoamericanos Rómulo Gallegos, 1980), II, 62-65.

${ }^{61}$ La opinión del primero aparece en Primer encuentro de narradores peruanos (Lima: Casa de la Cultura del Perú, 1969), p. 242; y la de los segundos, en Luis Harss, Los nuestros (Buenos Aires: Sudamericana, 1968), pp. 21, 302; Emir Rodríguez Monegal, Narradores de nuestra América (Montevideo: Alfa, 1969), I, 1973; y Mario Vargas Llosa, «Novela primitiva y novela de creación», Revista de la Universidad de México, XXIII, 10 (junio de 1969). Cf. Antonio Cornejo Polar, Literatura y sociedad en el Perú: La novela indigenista (Lima: Lasontay, 1980), pp. 26, 67-68 y passim. 
